\title{
DETEKSI DINI BAGI GURU UNTUK PERILAKU BULLYING SISWA DI SMA MUHAMMADIYAH I JOMBANG
}

\section{EARLY DETECTION TEACHERS FOR STUDENT BULLYING BEHAVIOR IN SMA MUHAMMADIYAH I JOMBANG}

\author{
Shanti Rosmaharani, SKep,Ns,M.Kep \\ Sekolah Tinggi Ilmu Kesehatan Pemkab Jombang \\ email: shantirosmaharani@gmail.com
}

\begin{abstract}
ABSTRAK
Remaja mulai melakukan hubungan interpersonal dengan orang lain dan biasanya yang paling sering adalah dengan teman sebaya dan membentuk peer group. Keluarga memiliki peranan penting dalan sosialisasi remaja, tentang bagaimana nilai moral dan etika yang baik ditanamkan sejak dini oleh keluarga. Bila sosialisasi nilai yang ditanamkan keluarga kurang dipahami dan dimengerti oleh remaja, maka bisa jadi perkembangan perilaku dan psikososialnya bermasalah. Akibatnya, remaja mulai menunjukkan gejala patologis perilaku perilaku beresiko lainnya, salah satunya adalah bullying dan kenakalan remaja.Tujuan dari kegiatan ini adalah. mengetahui secara awal perilaku bullying pada siswa sehingga dapat mendeteksi kejadian bullying sejak awal dan menghindari dampak yang negatif bagi korban dan pelaku.Hasil dari kegiatan ini adalah guru yang berperan sebagai pendidik tidak hanya bertanggung jawab pada nilai akademis siswa, tetapi juga memiliki tanggung jawab dalam membentuk tingkah laku dan karakter siswa. Guru berperan serta aktif dalam kegiatan ini dan sudah dapat mendeteksi prilaku bullying pada siswa. Pada kasus bullying yang terjadi pada siswa, guru berhak dengan segera melakukan berbagai tindakan untuk merespon perilaku bullying siswa agar terhindar dari berbagai macam kekerasan.
\end{abstract}

Kata Kunci: deteksi dini, bullying, guru

\begin{abstract}
Adolescents begin to have interpersonal relationships with other people and usually the most common is with peers and form peer groups. The family has an important role in the socialization of adolescents, about how good moral and ethical values are instilled by the family from an early age. If the socialization of values instilled in the family is not understood and understood by adolescents, it could be that their behavior and psychosocial development are problematic. As a result, adolescents began to show pathological symptoms of other risky behaviors, one of which was bullying and juvenile delinquency. The purpose of this activity is. knowing in advance bullying behavior in students so that it can detect bullying incidents from the start and avoid negative impacts on victims and perpetrators. The result of this activity is that teachers who act as educators are not only responsible for students' academic scores, but also have responsibility in shaping student behavior and character. Teachers participate actively in this activity and can detect bullying behavior in students. In cases of bullying that occur to students, the teacher has the right to immediately take various actions to respond to student bullying behavior in order to avoid various kinds of violence.
\end{abstract}

Keywords: early detection, bullying, teacher

\section{PENDAHULUAN}

Bullying merupakan salah satu perilaku agresif yang ditunjukkan atau dilakukan seorang kepada orang lain. Perilaku bullying bertujuan menyakiti seseorang baik secara fisik atau secara psikologis, pelaku bullying biasanya dilakukan oleh orang atau kelompok yang merasa lebih kuat kepada orang atau kelompok yang lebih lemah (Yunika, Alizamar \& Sukmawati, 2013)

SEJIWA dan Plan Indonesia melakukan survey yang melibatkan 1500 orang siswa pelajar SMP dan SMA di 3 kota besar, yaitu Jakarta, Yogyakarta, dan Surabaya tahun 2008. Survei menunjukkan hasil bahwa $67,9 \%$ pelajar Sekolah Menengah Atas dan 66,1\% di tingkat Sekolah Lanjutan Pertama pernah melakukan 
ancaman dan kekerasan. Kekerasan yang dilakukan antar sesama siswa tercatat sebesar 41,2\% untuk tingkat SMP dan 43,7\% untuk tingkat SMA dengan peringkat paling tinggi yang berupa tindakan pengucilan.

Perilaku bullying adalah kekerasan yang berdampak negatif bagi korban dan mempengaruhi emosional anak. Hal itu dibuktikan dengan adanya ketidak seimbangan kekuatan antara pelaku dan korban dengan tujuan untuk menyakiti korban secara mental atau fsik (Wiyani, 2012). Deteksi dini sangat diperlukan untuk mencegah perilaku tersebut dalam hal ini pihak sekolah terutama guru memegang peranan yang sangat penting. Besarnya dampak buruk yang ditimbulkan perilaku bullying ini, membuat bully harus dapat dikenali sejak dini. Program anti kekerasan/bullying harus dimulai sejak dini karena hal tersebut dirasa efektif dalam membentuk perilaku anak.

\section{METODE PELAKSANAAN}

Kegiatan pengabdian masyarakat deteksi dini bullying pada tanggal 28 Januari 2019 Kegiatan ini diadakan untuk mengetahui secara awal perilaku bullying pada siswa. Kegiatan yang dilakukan dengan melalui 3 tahap, antara lain:

\section{Kegiatan pendahuluan: (30 menit)}

- Peserta masuk keruang kelas

- Peserta mengisi daftar hadir

- Perkenalan antara pelaksana dan peserta

- Stimulasi atau brainstorming

\section{Kegiatan inti: (70 menit)}

- Memberikan penjelasan perkembangan remaja

- Memberikan penjelasan perilaku bullying

- Mencontohkan deteksi dini pada siswa terkait perilaku bullying

- Pemberian hadiah/sovenir kepada peserta guru

- Feedback/ umpan balik atas manfaat dilakukannya deteksi dini pada siswa terkait perilaku bullying

Kegiatan penutup: (20 menit)

- Mengulas kembali tentang perilaku bullying .

- Penutup/ pembacaan doa dan salam

Sasaran Kegiatan Pengabdian Masyarakat
Seluruh tenaga pendidik di SMAMuhammadiyah I Jombang yang berjumlah 25 guru.

\section{HASIL KEGIATAN}

Kegiatan pengabdian masyarakat ini dilaksanakan di SMA Muhammadiyah I pada tanggal 28 Januari 2019 yang diikuti oleh seluruh guru SMA Muhammadiyah I Jombang. Kegiatan diawali dengan pembukaan yang disampaikan oleh waka kurikulum, dilanjutkan pemaparan materi dan evaluasi oleh dosen. Sasaran kegiatan pengabdian masyarakat adalah seluruh guru SMA Muhammadiyah I Jombang. Seluruh guru merespon dengan baik dan mendengarkan pemaparan dari pelaksana dengan antusias. Setelah kegiatan selesai, pelaksana mengevaluasi kembali kegiatan yang telah dilakukan untuk mengetahui pemahaman guru.

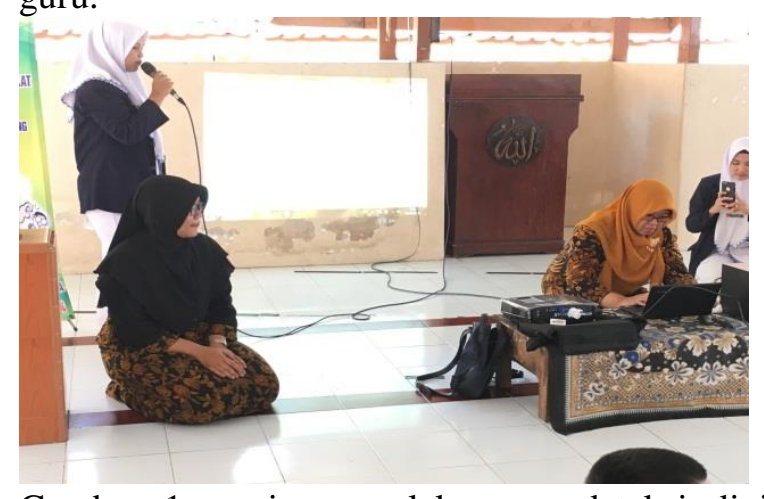

Gambar 1 persiapan pelaksanaan deteksi dini bagi guru untuk bullying siswa di SMA Muhammadiyah I Jombang

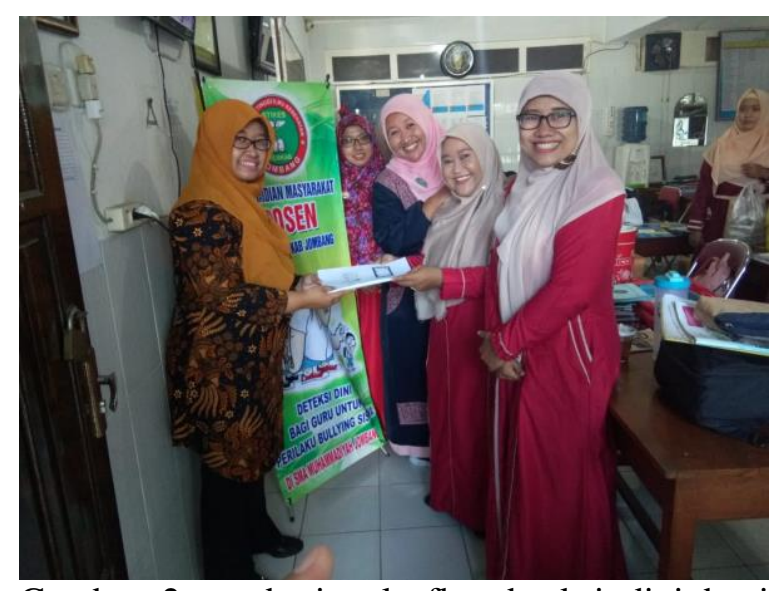

Gambar 2 pemberian leaflet deteksi dini bagi guru untuk bullying siswa di SMA Muhammadiyah I Jombang. 


\section{PEMBAHASAN}

Perilaku bullying di sekolah yang terjadi pada siswa dapat diakibatkan dari banyak faktor salah satunya adalah yaitu kurangnya kasih sayang dan perhatian orang tua, hubungan orang tua dan anak yang buruk dan faktor individu yaitu menyerang terlebih dahulu dan bersikap agresif dan negatif, sebelumnya pelaku bullying berasal dari korban yang pernah mengalami perilaku bullying, dan memicu orang lain untuk melakukan perilaku bullying pada siswa.

Bentuk perilaku bullying yang didapatkan dari hasil penelitian yakni bullying verbal, bullying fisik, bullying elektronik dan bullying relasional. Bullying verbal meliputi mengejek, mengolok tentang kekurangan fisik siswa dan menggunakan kata-kata kasar dan tidak menyenangkan, bullying fisik seperti memukul, menendang, mendorong dan mengambil paksa milik orang lain.

Guru berperan sebagai tenaga pendidik tidak hanya bertanggung jawab pada kemampuan kognitif siswa, namun juga mempunyai tanggung jawab dalam membentuk karakter siswa dan memberikan contoh bagaimana siswa berperilaku (Widayanti, 2009).

Pada bullying yang terjadi pada siswa, guru dapat melakukan berbagai tindakan dengan segera untuk merespon perilaku bullying siswa agar terhindar dari berbagai macam kekerasan. Sesuai dengan amanah Undang-Undang Republik Indonesia Nomor 23 Tahun 2002 tentang Perlindungan Anak, pasal 4 yang berbunyi "Setiap anak berhak untuk dapat hidup, tumbuh, berkembang, dan berpartisipasi secara wajar sesuai dengan harkat dan martabat kemanusiaan, serta mendapat perlindungan dari kekerasan dan diskriminasi”.

Kegiatan deteksi dini bagi guru di harapkan dapat membantu guru dalam mendeteksi kasus secara dini sehingga dapat meminimalkan dampak buruk bagi siswa. Guru juga dapat melakukan konseling pada pelaku dan korban, sehingga mengurangi efek traumatis bagi siswa.

\section{KESIMPULAN}

1. Deteksi dini bagi guru untuk perilaku bullying siswa di SMA Muhammadiyah I Jombang sangat penting dilakukan agar pihak sekolah dapat mengantisipasi akibat yang akan terjadi dari perilaku bullying.

2. Penanganan dan tindak lanjut juga diperlukan ketika sudah diindikasikan ada perilaku bullying oleh siswa di sekolah.

\section{SARAN}

Saran untuk pengabdian masyarakat ini adalah diperlukan dukungan dari pihak sekolah untuk secara rutin mendeteksi perilaku siswa yang menyimpang terkait dengan bullying, agar tidak berdampak fatal bagi pelaku dan korban.

\section{DAFTAR PUSTAKA}

Wiyani, N.A. (2012). Save Our Children from School Bullying. Yogyakarta: Ar-ruzz Media

Indawati (2016).Upaya Guru Kelas Untuk Mengatasi Perilaku Bullying Pada Siswa Kelas IV Di Sekolah Dasar Islam Lukman Hakim Pakisaji Malang. Skripsi. Malang. Universitas Islam Negeri Maulana Malik Ibrahim

Widayanti (2009). Fenomena Bullying di Sekolah Dasar Negeri di Semarang Sebuah Studi Deskriptif.Jurnal Psikologi Undip. Vol 5

Yunika, Alizamar \& Sukmawati, (2013). Upaya Guru Bimbingan Dan Konseling Dalam Mencegah Perilaku Bullying Di SMA Negeri Se Kota Padang. Jurnal Ilmiah Konseling. Vol 2 No3 